Western University

Scholarship@Western

FIMS Publications

Information \& Media Studies (FIMS) Faculty

2014

\title{
Indie media and digital community collaborations in public libraries
}

Jen Pecoskie

Wayne State University

Heather Hill

Western University, hhill6@uwo.ca

Follow this and additional works at: https://ir.lib.uwo.ca/fimspub

Part of the Library and Information Science Commons

Citation of this paper:

Pecoskie, J. \& Hill, H. (2014). Indie media and digital community collaborations in public libraries. Collection Building33(4), 127-131. 


\section{Indie media and digital community collaborations in public libraries}

\section{INTRODUCTION}

Traditionally, public libraries' collection development staff gathers information from publishers and vendors and, using their distinct expertise, determine items suitable for the collection and present these materials to patrons. In addition, economies of scale have led many public libraries to centralize collection development, using approval plans and blanket orders that focus on large publishing houses and media companies. This consolidation of content providers and use of approval plans offer convenience from a library workload standpoint. In addition, titles from these larger companies are more likely to be known of, popular, and thereby requested by patrons, most likely due to marketing strategies. Offerings from smaller publishing and media companies require additional effort to discover by both collecting staff and library users.

The significant growth and subsequent adoption of digital media has created new limitations and possibilities for the future of public library collections. Large publishing companies have placed significant restrictions on the digital media content available to libraries. At the same time, the digital media tools have provided a wealth of new content available for collections from smaller media creators as well as allowing for significant content creation locally within libraries' communities. While our focus here is significantly on books, digital media has also created new opportunities for music, again, both local and non-locally created. These "fringe" or nontraditional digital media are cultural products produced for consumption and reception, therefore, within library and information science (LIS), it is essential to consider which materials fit into 
contemporary collections, how they are connected to public libraries, and subsequently are made available to library users.

After a brief overview of the limitations and opportunities of digital media, this paper explores three related areas. The first area focuses on small and independent content providers that are actively seeking to collaborate with libraries. The second is on how some public libraries are actively responding to the limits placed on digital media by publishers and how they are using digital media to help their communities create new content. And the third area focuses on how one set of librarians' tools -- reviewing sources, including user-generated content -- hinder and help as a discovery tool for exploring some of these digital media for collections. We offer suggestions for expanding collection development practices in order to capture cultural products from these sources.

\section{LIMITATIONS ON DIGITAL MEDIA FROM LARGE CONTENT PROVIDERS}

While all of the 'Big Five' publishers offer ebooks to libraries, in most cases the titles are offered only through restrictive leasing agreements. In 2011, Harper Collins, made the decision that ebooks must be 'repurchased' by libraries after 26 circulations (American Libraries, 2013). While Hachette makes its full catalog list of ebooks available for single-user borrowing, titles are priced 300\% higher than the paper version (American Libraries, 2013). Furthermore, there are selection and variety challenges with ebook catalogs, as well as significant access issues as digital media is often saddled with the limitations of the print medium and further hampered as 'right of first sale' is eroded. Few publishers offer an ownership model for digital media. Similar 
situations are occurring with various examples of digital media, including audiobooks, video, and music.

\section{NEW OPPORTUNITIES WITH DIGITAL MEDIA}

While significant limitations exist with large, traditional publishing and media companies, digital media has also created new opportunities for library collections. Digital media have significantly increased access to independent (indie) media such as music and ebooks from small producers, artists, publishers, and indie authors. The genres covered by indie media are just as diverse as those in traditional media from non-fiction to fiction and from classical to heavy metal. Many of these creators, as will be shown below, are actively interested in working with libraries.

Indie media is used here as an umbrella term that incorporates a variety of publishing varieties, from small, print, independent, traditional publishing houses to self-published authors who publish digital works on their own websites or through a self-publishing platform. Because of their size, small, traditional presses are not often included in vendor catalogs. Self-published authors vary widely in their approach. Some have formed collaborations to present an imprint to the public (e.g., Collective Inkwell), while others publish through a self-publishing platform like Smashwords.

The traditional perspective of self-published materials is that they are of inferior quality and a product of a predatory industry, commonly termed 'vanity presses' (Hadro, 2013). The original vanity presses focused largely on separating an unknown writer from his or her money. More recently, print self-publishing has lost ground to online, ebook self-publishing platforms and the 
stigma once attached to such endeavors is quickly disappearing. Authors such as Amanda Hocking and Hugh Howey have had success selling titles directly to readers through Amazon. With regard to these operating definitions, the borders are fluid and parties involved may use multiple modes of publishing in order to make their works available. For example, Hugh Howey has signed with Simon and Schuster to publish his Wool novels in paper format, but has retained the ebook rights so he can continue to sell them independently (Wecks, 2012).

What once was an onerous task, finding and learning about small and indie media, is significantly easier using the internet as a discovery tool. In addition, there has been an explosion of self-published ebooks that are of significant interest to publishers and readers since the phenomenal success of the Fifty Shades of Grey trilogy (James, 2012a; 2012b; 2012c). The inclusion of self published media alongside their traditionally published counterparts in online bookstores like Amazon, Barnes and Noble, iBooks, and Kobo mean that readers -- who may not even recognize that they are reading self-published materials -- are also finding independent works more easily.

In addition to already existent materials, digital media provides opportunities to create new works in new ways and offers easy opportunities for distribution. This takes on a user-centred publishing model where the necessary infrastructure and tools are in place for unaffiliated users to not only create in whichever medium they select (or combine), but to make public their works. 
As we have (briefly) examined the current state of cultural production and publishing, it is essential to reflect on the changes occurring within the industry and how these changes are affecting public library collections. This is where we now turn, as we explore the ways in which these two areas are intersecting in order to develop a more comprehensive understanding of opportunities available to expand collections with digital media and contemporary content creators.

\section{INDEPENDENT COMPANIES PARTNERING WITH LIBRARIES}

Our examination of current practices found that certain independent companies are actively courting libraries. These independent music vendors and publishers are interested in working with libraries to get their products exposed to wider audiences. These types of materials significantly increase the variety of resources that users have access to within collections.

\section{Case profiles}

Magnatune is an independent music vendor that provides its catalog to libraries under a Creative Commons license. The catalog consists of more than 1000 albums of varied genres ranging from classical to punk. Magnatune actively directs promotion to libraries (http://magnatune.com/info/libraries) as it offers their entire music catalogs to libraries under generous terms where the music resides on the library's servers and user downloads never expire.

Indie ebook distributor Smashwords (http://www.smashwords.com/) proclaims they, "proudly supports libraries, and we're working to make our ebooks available to every library in the world" 
(Smashwords, n.d.). Authors whose works are distributed through Smashwords can set different prices for end users and libraries. A small survey of Smashwords authors in 2012 found that $56 \%$ of authors would charge libraries less than retail or give libraries their works for free (Smashwords, 2012). Libraries can select individual titles from the full catalog, or select from large number of titles (e.g., the top-rated 10,000 titles) and can custom filter the titles by category and price range.

In addition to independent authors and distributors, some traditional, small presses are working to build relationships with libraries. As an example, the Poisoned Pen Press, an independent publisher and one of the largest publishers of the mystery genre, offers an open invite to libraries to embed these small press titles into collections (http://www.poisonedpenpress.com/libraries/).

Dzanc Books offers innovative and award-winning literary fiction in physical and ebook formats and is a leader in the electronic publishing industry. Dzanc is a strong advocate of libraries and "understands the benefit of working with libraries as libraries continue to serve an invaluable role in getting worthy books into the hands of the public" (http://www.dzancbooks.org/librarypartners/) and welcomes inquires from libraries (public, private, and university) to collect their 3000 plus titles. As a partner of libraries and library patrons the publisher does not place lending restrictions on the material and permits libraries to continue checking titles out to patrons forever. Further, the ebook titles are not restricted, are available DRM-free, and provided in formats compatible with all currently used devices (Dzanc Books, n.d.) 
These case profiles offer only a selection of the more high-profile independent companies actively seeking to add their digital content to public libraries' catalogs. Unfortunately, there are no discovery tools for LIS professionals that list these types of organizations. Discovering these indie and small media companies requires seeking out individual companies, their catalogs, and starting a dialog.

\section{PUBLIC LIBRARIES EXHIBITING A NON-TRADITIONAL APPROACH}

Given the current challenges and opportunities provided by digital media, what are public libraries doing regarding non-traditional materials? It is not unusual for public libraries to collect traditionally published materials from local authors, but what about lesser-known, non-local authors published non-traditionally?

In this examination of current practices, we searched for exemplar public libraries that are actively collecting digital media from small, independent, and local providers. Within the set of libraries we found examples that are actively shifting away from the limitations of large digital media providers, those that are focused on collecting local content, and those that are actively working to help their communities create new content. We turn our focus to these case profiles to illustrate contemporary situations.

\section{Case profiles}

Douglas County Libraries (DCL), a public library system in Colorado, has publicly dismissed the high costs of ebooks for public libraries (Douglas County Libraries, n.d.(a)). In focusing away from the limitations of large content providers, DCL is actively seeking out smaller and indie 
media providers that are more flexible with their contracts. Part of their response is the development of an ownership model for ebooks in which the library hosts material, as opposed to the vendor or publisher, from 18 publishers and video companies that produce material of varying genres and for various ages directly on their site, and the titles are loaned out for a specific period of time similar to other ebook contracts.

This shift to hosting content has required DCL to develop their own platform for ebooks. They have spent an estimated $\$ 100,000$ to develop their own content hosting platform based on Adobe DRM for authentication. In addition, they are working on creating a model that can be used by other libraries wishing to host their own content. The ebook content hosted by DCL is broad ranging. It includes such material as mystery titles from Poisoned Pen Press, children's materials from Crabtree Publishing, 10,000 titles of varying genres from Smashwords, and other independent/self publishers.

DCL is extending their emphasis on collecting digital content towards the local, as the library is also starting classes focused on the writing, editing, publishing, and marketing of ebooks. In addition, they are offering to add these newly created books from members of the community to their collection (Douglas County Libraries, n.d.(b)).

Most libraries will likely not have access to $\$ 100,000$ to develop a new system, but that does not mean that they cannot be a part of these types of initiatives. Los Gatos Public Library in California seems to have taken a different path than DCL to add self-published ebooks to their catalog. They have partnered directly with Smashwords to provide programming on self- 
publishing. Local authors who want to donate their Smashwords-published ebooks to the library must add appropriate metadata to their texts in order to be accepted in Smashwords 'Premium' catalog. The library then requests the title from the digital distributor OverDrive.

Similarly, the Sacramento Public Library (SPL; California) acknowledges the public library as a space for creation, cultural production, and celebration of local content. Instead of only acquiring already existing items, SPL is supporting the creation of new content through their initiative called 'I Street Press' (http://www.saclibrary.org/istreet/). This is a community-writing center centralized through the use of their Espresso Book Machine where authors can witness their book being produced (printed) into tangible format. SPL supports this content creation initiative by hosting classes on writing, editing, and publishing. Those community-based authors who publish their book through their Espresso Book Machine can place their book on the Espresso Book Machine Network catalog for sale outside of the local area.

Multiple libraries are connecting their communities and collections through music initiatives. Kent District Library (KDL; Michigan) offers a "Local Indie" collection which features donated books, music, and films from local independent authors and artists. The focus for KDL is on collecting physical media such as books, CDs, and DVDs for their users. The Ann Arbor District Library (AADL; Michigan) has contracted with independent music vendor (http://magnatune.com/) to acquire access and ownership of the Creative Commons licensed Magnatune music catalog. This is provided in digital form for users. Iowa City Public Libraries (ICPL; Iowa) created the Local Music Project (http://music.icpl.org/). ICPL purchases music from local Iowa City musicians and hosts the digital material on their site. Users can download 
the music in a similar fashion to how they download other digital media, but users keep the downloaded music. Currently, there are more than 130 albums available from a wide range of genres available.

Other related initiatives are happening more broadly at the regional and state level. E-voke: Creating the future for library e-content (http://evoke.cvlsites.org/) is a group that consists of the Colorado State Library, the Colorado Library Consortium, the Colorado Alliance of Research Libraries, Douglas County Libraries, and Marmot Library Network. This task force came together to develop e-book ownership models that provide information on software and technologies being used to host e-book lending platforms as well as draft letters to publishers and draft agreements. E-voke provides open access to their documentation so that other libraries can build off of their groundwork. The Library Publishing Toolkit (http://www.publishingtoolkit.org/) is an initiative out of New York with partners from Milne Library SUNY Genesco, and the Monroe County Library System. The toolkit is an effort to identify trends in library publishing and seek out best practices. The toolkit is Creative Commons' licensed and free to download.

\section{PROFESSIONAL REVIEWING SOURCES AND INDEPENDENT EBOOKS}

Given that there is a movement afoot in some libraries to embed independent, self-published, and local cultural products into collections in order to give users enhanced access, what must be done in the practice of collection development? How are collections and acquisitions changing and what tools can professionals rely on? How are these non-traditional items to be defined as suitable for collections? These questions are of utmost importance as we consider the changing 
creation and publishing cycle and the varied media initiatives that are binding public libraries with indie projects.

Non-traditional materials are generally more challenging to access, as they are not a part of approval plans and conventional professional tools for selection of materials generally do not include these non-traditional materials. Of focus for this section are indie and small press ebooks.

Publications that provide traditional reviewing services generally do not accept self-published materials. Of the few that do include these materials the number of self-published reviews are limited within the scope of the publication or author(s) must pay for the reviews inclusion (e.g., https://www.kirkusreviews.com/author-services/indie/). Reviewing publications that focus exclusively on self-published works are limited in number, in fact, our research uncovered one example, ForeWord Reviews (https://www.forewordreviews.com/). Others, like Kirkus and Publishers' Weekly, offer some coverage of self-published material. The limitations of these traditional reviewing resources necessitates looking at other sources, especially non-standard tools that provide a platform for user generated content.

\section{USER-GENERATED CONTENT FOR COLLECTION DEVELOPMENT}

User generated content (UGC), as a social media initiative, often exists as comments and other utterances produced by users and can be harnessed in order to better understand the nuances, opinions, and preferences of users. UGC allows for non-LIS-professional voices to be heard, offering interpretation and feedback in a variety of contexts. We are not arguing here that social media and UCG are under-used tools in public library collection development, instead, we 
advocate for their increased use as a tool to find and evaluate non-mainstream materials for inclusion in collections.

Social media sites which focus on reading, such as Goodreads (https://www.goodreads.com/) or LibraryThing (https://www.librarything.com/), are relevant to collection development as these sites offer a larger number of number of reviews than traditional sources and also provide opportunities for community sharing about what readers want, like, or dislike from their reading, including authors, series, and titles. Goodreads includes traditionally published titles, and is currently used for collecting these titles, but Goodreads also includes independent or selfpublished titles in the database. Such UGC may be the only significant discovery tool for selfpublished material.

For example, Dust by Hugh Howey (Howey, 2013) was originally self-published and there are over 1500 reader reviews about this title on the Goodreads platform (Goodreads, 2014). Integrating UGC to collection development practice more widely expands the scope and nature of the reviews that are available for both readers and LIS professionals to mine. In fact, it would appear that some libraries understand the power of UCG to build reading communities as they embed the ability for users to offer comments directly into their catalogs with the use of social catalogues (e.g., Bibliocommons social discovery platform, http://www.bibliocommons.com/). As well, Douglas County Libraries is choosing to maintain a set of Volunteer Reviewers in order to increase community voice and response within their own library catalog (Douglas County Libraries, n.d.(c)). These reviewers populate the collection with reviews to encourage other patrons to expand their reading. 
In collection building work, the reviewing and vetting of material is usually performed by a professional who may investigate items directly or indirectly through the use of professional reviews (if multiple reviews are available), or the vetting may be left to a vendor's approval plans. Instead of relying more on the professional perspective, the approach of more firmly integrating the user perspective through UGC into practice unveils a 'global' voice that helps with uncovering potential material for library collections. This approach then, is a "bottom up" versus "top down" approach and it preserves and privileges the voice of the reader, whereas before the voice of the 'professional' was considered more suitable and appropriate. What is required then is a shift in perspective about what is valued or 'good' and to tools used to determine these, including the non-professional stance and the impact and validity of the collective user voice.

UGC is, perhaps, most acceptable when analyzing materials that have gone through the traditional publishing process. But, for indie and self-published materials a greater leap of faith may be required. UGC, in many cases, is the only aid to discovery for these materials. As such, UGC must be critiqued and analyzed about what information is contained within it and what can be learned from it. Following this, then, we advocate, that for professional use in this context, the unit of analysis is in the overview of a mass set of UGC and not in an individual review.

\section{CONCLUSION}

This work advocates for building upon current collection development practices to find suitable approaches that allow for digital community collaborations in public libraries. This approach 
allows for collections at libraries that are interested in collecting digital media (including further developing those collections profiled in this work) to expand, while maintaining an open approach to the changing publishing and digital media cultural production realms. Going beyond traditional publishers and purveyors, towards the small, indie, and localized, necessitates getting away from some of the traditional collection development tools and further delving into UGC in order to apply collective, community perspectives alongside LIS professionals' work.

Certainly, we acknowledge that some of what we present is not new for public libraries. The practice of including local material is not necessarily innovative. There is a long history of public libraries hosting literary groups, writing groups, and authors of varied types, especially those from the local community. Small and indie presses have always had some representation in public libraries. But the limitations set by large media producers for their digital content coupled with the explosion of digital indie and small producers eager to partner with libraries provide an opportunity to expand this aspect of public library collections. This focus on the small, indie, and local has the potential to create contemporary collections that are diverse and unique and reflect the needs of library users. 


\section{REFERENCES}

American Libraries. (2013), "Big six publishers and ebook lending”, American Libraries available at: http://www.americanlibrariesmagazine.org/blog/dcwg-big-six-matrix-ebooklicense-comparisons (accessed 11 May 2014).

Brantly, J. S. (2010), “Approval plans, discipline change, and the importance of human intermediated book selection", Library Collections, Acquisitions, \& Technical Services Vol. 34, pp. 11-24.

Douglas County Libraries. (n.d(a)), “An open letter about eBooks and Douglas County Libraries", available at: http://douglascountylibraries.org/content/ebooks-and-DCL (accessed 11 May 2014).

Douglas County Libraries. (n.d(b)), “The Wire: A Writer's Resource”, available at: http://blogs.douglascountylibraries.org/thewire/ (accessed 11 May 2014).

Douglas County Libraries. (n.d(c)), “Ongoing Opportunities”, available at: http://douglascountylibraries.org/aboutus/volunteer/ongoing-opportunities (accessed 11 May 2014).

Dzanc Books. (n.d), "Partnering with libraries in both print and ebook publications", available at: http://www.dzancbooks.org/library-partners/ (accessed 11 May 2014). 
Goodreads. (2014), “Dust”, available at: http://www.goodreads.com/book/show/17855756-dust (accessed 11 May 2014).

Hadro, J. (2013), “What's the Problem with Self-Publishing”, Library Journal Vol. 138 No.7, pp. 34.

Howey, H. (2013), Dust, CreateSpace, https://www.createspace.com/4348121 (accessed 11 May 2014).

James, E. L. (2012a), Fifty shades darker, Vintage Books, New York, NY.

James, E. L. (2012b), Fifty shades freed, Vintage Books, New York, NY.

James, E. L. (2012c), Fifty shades of Grey, Vintage Books, New York, NY.

Smashwords. (n.d), "How to create, publish, and distribute ebooks with Smashwords", available at: http://www.smashwords.com/about/how_to_publish_on_smashwords (accessed 11 May 2014).

Smashwords. (2012), “Smashwords Pricing Manager Tool Enables Custom Library Pricing”, available at: http://blog.smashwords.com/2012/08/smashwords-pricing-manager-toolenables.html (accessed 11 May 2014). 
Wecks, E. (2012), "Ebook success Hugh Howey sells print rights to Wool”, available at: http://archive.wired.com/geekdad/2012/12/howey-sells-print-rights/ (accessed 11 May 2014). 